\title{
The History of Milk Pasteurization in Iran and the Role of Pasteur Institute in Its improvement
}

\author{
Sholeh Maslehat ${ }^{1}$, Ehsan Mostafavi ${ }^{*}$ \\ ${ }^{1}$ Department of Epidemiology and Biostatistics, Research Centre for Emerging and Reemerging Infectious Diseases, \\ Pasteur Institute of Iran, Tehran, Iran
}

Received Nov. 03, 2018; Accepted Dec. 25, 2018

\begin{abstract}
In November 1950, a relatively modern factory, called Alpha, was established in Javadiyeh district of Tehran. It was the first factory of milk pasteurization in Iran, which started by pasteurizing five tons of milk per day and manufacturing dairy products. The factory was under official health supervision of Pasteur Institute of Iran and had a significant contribution to the improvement of the quality of products. In 1958, the ministry of health established a central laboratory for monitoring of food products, which lifted the official supervision of the Pasteur Institute of Iran. In 1959, despite having advanced equipment, the factory was closed due to bankruptcy. This article tells the story of the first factory of milk and dairy products pasteurization in Iran and the challenges it faced. J Med Microbiol Infec Dis, 2018, 6 (4): 87-90.
\end{abstract}

Keywords: Health Promotion, Milk, Iran.

\section{INTRODUCTION}

The history of milk pasteurization. The term Pasteurization is derived from the name of the French scientist Louis Pasteur (1822-1895). In 1864, Pasteur showed that it is possible to prevent undesirable fermentation by heating the fluids for a few minutes at $57^{\circ} \mathrm{C}$. This type of fermentation is caused by bacteria present in the beverages, leading to their spoilage. The application of heat eliminates harmful bacteria. The discovery of the cause of fermentation led to the invention of milk pasteurization process, which increased the shelf life of healthy milk for consumers. Milk pasteurization also prevented the transmission of pathogens, such as Brucella spp., Coxiella burnetii, Streptococcus spp., Salmonella spp., Listeria spp., Escherichia coli, Campylobacter spp., and Staphylococcus aureus to humans [1-5]. Pasteurization neither significantly changes milk composition nor its taste and nutritional value [4].

Pasteurization of milk first began in Germany and Denmark in 1880, and then gradually expanded to Europe, America, and other countries. The first industrial pasteurization machines were built in 1895 [6, 7]. Establishment of milk industry in every country depended on factors, such as the existence of a suitable market for milk and dairy products, availability of skilled human resources, and constant supply of high-quality milk [8]. In the twentieth century, the advances in bacteriology led to the development of more approaches to control diseases and harmful bacteria [1, 9].

Other inventions, such as refrigerators, milking machines, and accessories such as mixers, paper and glass containers, bottle filling devices, large tanks, and milk trucks have further contributed to the growth of pasteurized milk industry [10].
Establishment of Alpha Milk factory in Iran. Nearly 55 years after the launch of the first pasteurization milk factories in the world, Alpha pasteurized butter-milk factory was established in November 1950 by Aram Boodaghian [11]. Born in 1900, he was the son of Gabriel Boodaghian, merchant and benefactor from the Armenian community of the Azerbaijan region. In the fifteenth (19471949), sixteenth (1950-1953), and eighteenth (1953-1956) parliament, he was the representative of the Armenians of Tehran and the north of Iran (Figure 1) [12].

Built-in Javadieyeh district down the Tehran railway station, the Alpha Pasteurized butter-milk factory was the first modern Iranian milk factory, which started its work by daily pasteurizing of five tons of raw milk and converting it into a variety of dairy products. With equipment, such as the cream separator, pasteurizing machine, and bottle filler, the Alpha factory was considered a large factory. Its bottlewashing machine was a semi-automatic and straightforward device. Moreover, it had rinsing solutions tanks for and motorized brushes for washing the inside and outside of bottles, both manually and automatically. After washing, the milk bottles were immersed in chlorinated water, rinsed, and used again [11].

\footnotetext{
${ }^{*}$ Correspondence: Ehsan Mostafavi

Department of Epidemiology and Biostatistics, Research Centre for Emerging and Reemerging Infectious Diseases, Pasteur Institute of Iran, No. 69, Pasteur Ave, Tehran, Iran, 1316943551.
}

Email:mostafavi@pasteur.ac.ir

Tel/Fax: +98 (21) 64112121 


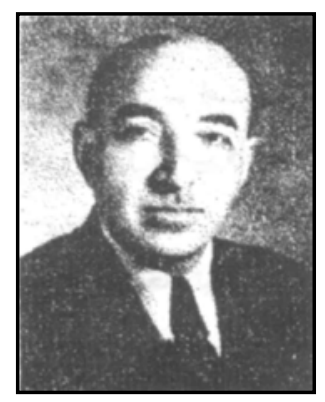

Fig 1. Aram Boodaghian, head and founder of Alpha Pasteurized Milk Factory in Iran

At the time of establishment, the owners of the factory asked the Ministry of Health for official supervision of the products. Dr. Najmabadi, head of the Inspection Department of the Ministry, and Dr. Marcel Baltazard, the director of the Pasteur Institute of Iran (Figure 2), were appointed to this task by the Ministry of Health, and the mission was registered on November 28, 1950.

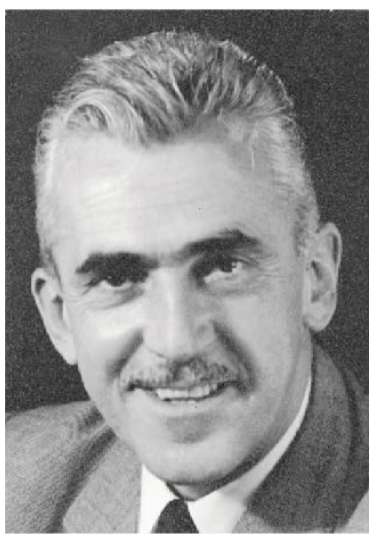

Fig 2. Dr. Marcel Baltazard, French director of the Pasteur Institute of Iran (1945-1960)

Pasteur Institute of Iran. With 33 members worldwide, the Pasteur Institute International Network, operating based on a joint mission, has been at the forefront of the fight against infectious diseases for more than a century.

In general, the activities of the members of this network are in the fields of research mainly on infectious diseases, public health, national and international cooperation, and interaction with the medical industry and society [13-15]. The Pasteur Institute of Iran, one of the oldest research and health centers in the country and the Middle East, was established in 1920 following an agreement between the Pasteur Institute of Paris and the Iranian government with the aim of providing health services in Iran.

Over nearly a hundred years of work, the institute has taken major steps in preventing and controlling infectious diseases in Iran and the world by conducting research on various infectious diseases and vaccines and creating different biological products [16].

Dr. Marcel Baltazard, a French physician, was the director of the Pasteur Institute of Iran (1945-1960). He redesigned the scientific and engineering structure of the
Institute and continued to serve as an advisor until 1962. He expanded his work by conducting research programs in Brazil, Peru, Burma, and Mauritania. He was appointed as an expert in the field of rabies (1959) and plague (1965) by the World Health Organization (WHO) [17].

Supervision of Pasteur Institute of Iran on Alpha factory. The first visit of Dr. Baltazard to the factory was on December 10, 1950. The owner of the factory signed a list containing suggestions for the improvement of Factory from the Pasteur Institute of Iran (Figure 3). The agreement between the factory and the institute included the right for Pasteur Institute of Iran to suspend the supervision if the factory did comply with the recommendations at the due time. The Institute would make the suspension public, a term never happened [11].

The factory was continuously inspected by the chairman and experts of the Pasteur Institute of Iran, and all the appliances, equipment, buildings, and products of the factory were examined regularly. In the first visits, the following changes in the ice production equipment and processing equipment were requested to be performed:

1. The factory committed to supply special metal containers for milk suppliers and sterilize them every day.

2. The factory had to provide a non-pressurized ironing machine and sterilize all bottles every day after washing.

3. The mechanical butter maker has to be sterilized before and after the work.

4. The heat recorder has to be repaired and used on a regular basis, and its documents should be reviewed by the inspector of the Pasteur Institute of Iran.

5. The factory water has to be examined, and if proven to be unhealthy, the depth of the well must be increased.

The factory started its work under the supervision of two experts (one German and one Iranian), and the Pasteur Institute of Iran was responsible for regular inspection of the factory and its products. The inspection of the factory and shops were carried out regularly by the inspectors of the institute. Safety notes for keeping dairy products were highlighted in each inspection (Figure 4). The factory was allowed to insert the phrase "Under the supervision of the Pasteur Institute of Iran" in its product labels (Figure 5). The supervision of the Pasteur Institute of Iran officially commenced in December 1950.

In the letter, Dr. Baltazard agreed on the Alpha factory to use the name of the Pasteur Institute of Iran products as the supervisor of the company in radio commercials. The popularity of the of the Alfa factory products among the people in Tehran led to an increase in the factory productions more demand for more raw milk.

The factory provided the best milk and milk products of Iran, which was unique in its kind.

The institute suggested a uniform for milk deliverers, and the consumers were assured of receiving healthy and fresh products in a cold chain. 


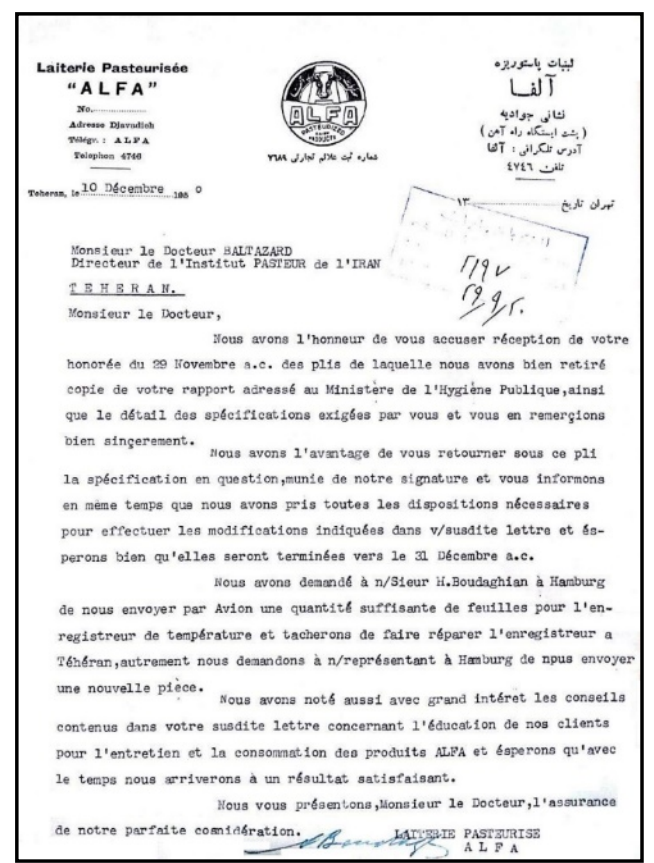

Fig 3. Letter from Mr. Aram Boodaghian, Head of the Alpha Pasteurized Milk Factory, to Dr. Marcel Baltazard, director of the Pasteur Institute of Iran, in December 1950. In this letter, Mr. Boodaghian explained the measures taken in response to the Institute's requests, for which he requested to obtain the Institute license.

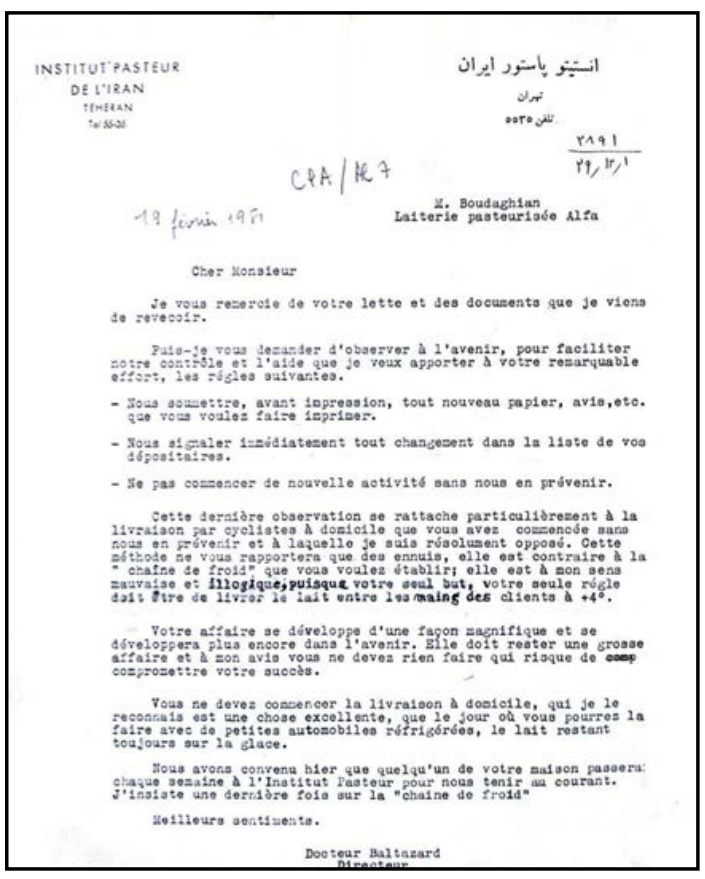

Fig 4. A letter signed by Dr. Baltazard in March 1950, in which he emphasized on the accomplishment of the remaining terms for receiving the PII license.

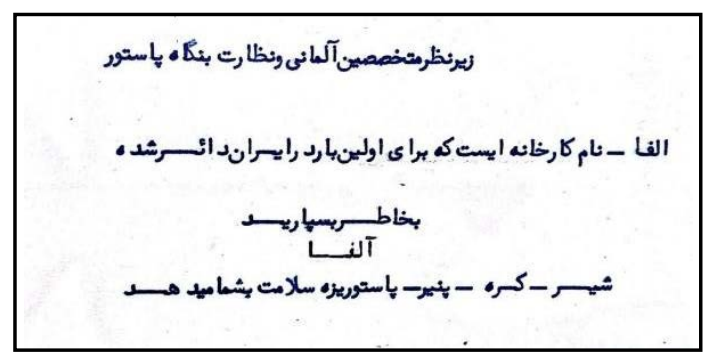

Fig 5. An advertisement that was approved by the Pasteur Institute of Iran. It reads, remember milk, butter and cheese of Alfa make you healthy.

Dr. Baltazard wrote letters to the factory, specifying instructions for improving milk quality and necessary changes. The following is an example of the letters: "It is desirable to place milk bottles, butter, yogurt, cheese, and other products on the ice and in heat-insulated trucks. The milk previously distributed and not used must be collected. In this way, the circulation and distribution of milk should be carried out before 9 AM".

On Feb 20, 1951, in a letter to the director of factory Dr. Baltazard wrote: "There are reports of the distribution of milk by bicycle without keeping the cold chain, which is against the instructions made by Pasteur Institute of Iran. He requested that all activities to be suspended until such kind of distribution was abandoned. Dr. Baltazard highlighted that the distribution of milk should be carried out with small cars equipped with a refrigerator, and emphasized that the factory must write a report to Pasteur Institute of Iran every week. Following this reminder, the distribution of milk by bicycles was abandoned, and small refrigerator cars were replaced. Furthermore, the path of the trucks that distributed the Alpha products was specified (Figure 4).

The Pasteur Institute of Iran also provided guidelines for distributors and vendors. The former was forced to get electricity licenses for their shops and refrigerators. On March 28, 1950, the list of distributors was presented to the Pasteur Institute of Iran. After inspection, 26 out of 37 distributors were approved.

The Institute approved the protocol for sterilization of washed bottles with disinfecting machines. For sterilization, the bottles were primarily washed with bleach and then were rinsed with plenty of water. The bottles were allowed to dry for the next morning, and all devices and work surfaces were washed with bleach. Every week, the fermentation materials used in butter production were delivered to the factory by the Pasteur Institute. The engineers of the factory provided the production process of various cheese for the Pasteur Institute of Iran, and the Institute's views on the processes were applied. 
Alpha factory closure. After 8 years of cooperation, began in 1957, the Pasteur Institute of Iran officially ended its supervision over the Alpha factory due to the establishment of a government laboratory to control food products. Despite the suspension of official supervision, the Institute continued to offer its proposals to Alpha factory officials. In the same year, the owners of the factory faced with financial distress. The factory lost its German expert, and the maximum pasteurization capacity of the factory reduced to15 tons per day. In 1958, even though the factory was very modern, it was shut down due to bankruptcy.

The last letter from Dr. Balthazar about Alpha milk factory was in response to Tehran prosecutor's request to shut down the factory due to lack of proper supervision and problems with some devices. Dr. Balthazar believed that the lack of appropriate care or maintenance of some equipment that could be fixed within a few days should not have been the primary cause to shut down the factory.

Current situation of pasteurized milk production in Iran. At the time of factory closure, several factories that produced dairy pasteurized products were established around the country. In 1954, the establishment plan of Tehran's pasteurized milk factory was developed by the Ministry of Health, and UNICEF. The factory started its work in 1957 with an initial capacity of 45 tons per day. In 1959, the second pasteurized milk factory with a capacity of 3 tons per hour was established in Tehran. By increasing demand for pasteurized products, milk pasteurization factories began to work in Tehran and other cities. After the Islamic Republic of Iran revolution in 1979, The Iran's Milk Supply and Distribution Company merged with seven milk factories in provincial capitals and formed Iran Dairy Industries Corporation. Now, Iran Dairy Industries Corporation has 16 factories operating in 13 large provinces of the country. Since 2001, the company has been selling its products under the brand of Pegah. Today, pasteurized dairy products are produced and distributed with other brands such as Damdaran, Mihan, Kaleh, Choopan, Ramak, Pak, Domino, and Haraz [11-14, 17-19].

\section{CONFLICT OF INTEREST}

The authors declare that there are no conflicts of interest associated with this manuscript.

\section{REFERENCES}

1. Fleming DW, Cochi SL, MacDonald KL, Brondum J, Hayes PS, Plikaytis BD, et al. Pasteurized milk as a vehicle of infection in an outbreak of listeriosis. N Engl J Med. 1985; 312 (7): 404-7.

2. Herbold JR. Emerging zoonotic diseases: An opportunity to apply the concepts of nidality and one-medicine. EHPM. 2005; 10 (5): 260-2.

3. Herbold JR, Steele JH, Murnane TG, Buntain BJ, Marano NN, Rossiter S, et al. Introduction; The history of public health and veterinary public service; Historic and future perspectives of the
American College of Veterinary Preventive Medicine; Blue ribbon task force report on the future of Food Safety and Inspection Service veterinarians: public health professionals for the 21st century; The National Antimicrobial Resistance Monitoring System (NARMS) for enteric bacteria, 1996-1999: Surveillance for action; Public health education of veterinarians and veterinary students for the future; Ten great veterinary public health/preventive medicine achievements in the United States, 1901 to 2000. AVMA. 2000; 217 (12): 1812-36.

4. Angulo FJ, LeJeune JT, Rajala-Schultz PJ. Unpasteurized milk: a continued public health threat. Clin Infect Dis. 2009; 48 (1): 93-100.

5. Geison G. The Private Science of Louis Pasteur Princeton University Press; 1995.

6. Steele JH. History, trends, and extent of pasteurization. AVMA. 2000; 217 (2): 175-8.

7. Bordenave G. Louis Pasteur (1822-1895). Microbes Infect. 2003; 5 (6): 553-60.

8. Holsinger V, Rajkowski K, Stabel J. Milk pasteurisation and safety: a brief history and update. Rev Sci Tech. 1997; 16 (2): 441-66.

9. Ackers M-L, Schoenfeld S, Markman J, Smith MG, Nicholson MA, DeWitt W, et al. An outbreak of Yersinia enterocolitica O: 8 infections associated with pasteurized milk. J Infect Dis. 2000; 181 (5): 1834-7.

10. Desta KB. Analyses of dairy cattle breeding practices in selected areas of Ethiopia: Köster; 2002.

11. Donya-e-Eqtesad. A look at the dairy industry in Iran 5 August 2018. Available from: https://www.donya-eeqtesad.com/fa/tiny/news-515587.

12. Lazarian JD. Encyclopedia of Iranian Armenians: Hirmand; 2009.

13. Dejman M, Habibi E, Eftekhari MB, Falahat K, Malekafzali H. Pasteur Institute of Iran an evaluation model. IBJ. 2014; 18 (3): 189.

14. Farazmand H. Production of milk, from traditional to industrial, 2014 [Updated 2019 February 16; Cited 2019 February 19]. Available from: https://www.smtnews.ir/report/457.

15. Mostafavi E, Bazrafshan A. Research and collaboration overview of Institut Pasteur International Network: a bibliometric approach toward research funding decisions. IJHPM. 2014; 2 (1): 21.

16. Enayatrad M, Mostafavi E. Pasteur Institute of Iran: History and Services. Res Hist Med. 2017; 6 (4): 209-26.

17. Keypour M, Behzadi MY, Mostafavi E. Remembering Marcel Baltazard, Great Researcher and the French President of Pasteur Institute of Iran. Arch Iran Med. 2017; 20 (8): 553.

18. Jameh Bozorg T, Fahlatpisha YF, Pestehee Z. The state of the country's dairy industry, Report, 2007 [updated 2007 August 20; Cited 2019 February 19]. Available from: http://mimasrd.ir/pdf/vaziat.pdf.

19. Pasteur I. Institute Pasteur International Network. 12 Dec 2018. Available from: https://www.pasteur.fr/fr/international. 